\title{
Aspiration pneumonia caused by fentanyl-induced cough -a case report-
}

\author{
Kyung Jee Lim, Soo Kyung Lee, Hyo Min Lee, Eun Young Park, Man Ho Kim, Yi Seul Kim, and \\ Mae Hwa Kang
}

Department of Anesthesiology and Pain Medicine, Hallym University College of Medicine, Anyang, Korea

\begin{abstract}
Although fentanyl-induced cough is generally transient and benign, it can give rise to serious problems in patients to whom increasing intracranial, intraocular or intraabdominal pressures may create dangerous situations. This case demonstrates aspiration pneumonia as a complication, exhibiting severe cough induced by intravenous injection of fentanyl. (Korean J Anesthesiol 2013; 65: 251-253)
\end{abstract}

Key Words: Aspiration, Cough, Fentanyl, Pneumonia, Vomiting.

Fentanyl is commonly used during induction of general anesthesia to attenuate hemodynamic response and catecholamine release during tracheal intubation. Intravenous administration of fentanyl, however, can elicit reflex cough with an incidence ranging from 18 to 68\% [1-6]. Fentanyl-induced cough (FIC) is not regarded as a significant anesthetic problem, as it is usually transient and benign. Sometimes, however, FIC is explosive or spasmodic and could cause serious consequences by increasing intracranial, intraocular or intraabdominal pressures in patients suffering ruptured cerebral aneurysms, head trauma, brain herniation or penetrating eye injuries. It would also be undesirable for those with severe airway responsiveness.

We report a case of a patient undergoing a laparoscopic nephrectomy, who experienced an unexpected vomiting and aspiration pneumonia, following severe cough that had developed after intravenous administration of fentanyl.

\section{Case Report}

A 32-year-old man (height $168 \mathrm{~cm}$, weight $66 \mathrm{~kg}$ ) was presented for a hand-assisted laparoscopic left nephrectomy for renal cell carcinoma. He has suffered from ulcerative colitis for 2 years and taken oral mesalazine daily. He was also diagnosed with diabetes mellitus 6 months ago, and his blood sugar levels have been well controlled by metformin. There was no history of allergies to food or drugs. He fasted for more than 8 hours before surgery and was given no sedative or opioid premedication.

When arriving at an operating room, the patient was monitored with an electrocardiogram, a non-invasive arterial blood pressure monitor and a pulse oximeter. Anesthesia was induced intravenously with thiopental sodium $350 \mathrm{mg}$, following preoxygenation with $100 \%$ oxygen. After confirming the loss of consciousness and self respiration, we mask-ventilate the patient with oxygen. Mask ventilation was performed without difficulty,

Received: August 6, 2012. Revised: 1st, August 29, 2012; 2nd, September 30, 2012. Accepted: October 2, 2012.

Corresponding author: Soo Kyung Lee, M.D., Department of Anesthesiology and Pain Medicine, Hallym University College of Medicine, 896, Pyeongchon-dong, Dongan-gu, Anyang 431-070, Korea. Tel: 82-31-380-3945, Fax: 82-31-385-3244, E-mail: agnetask@yahoo.co.kr (c) This is an open-access article distributed under the terms of the Creative Commons Attribution Non-Commercial License (http:// creativecommons.org/licenses/by-nc/3.0/), which permits unrestricted non-commercial use, distribution, and reproduction in any medium, provided the original work is properly cited. 
and he did not show any signs of airway irritation including cough. Vecuronium $10 \mathrm{mg}$ was given for neuromuscular block, and then fentanyl $100 \mu \mathrm{g}$ was administered. After a few seconds after the injection of fentanyl, the patient began to cough suddenly and vigorously. Coughing has persisted for about 30 seconds until he vomited a large volume of greenish fluid around the face mask. His head was immediately turned to the left and head down tilt of the table was applied. When vomiting ceased, after suctioning of the oral cavity and oropharynx, endotracheal intubation was achieved. During this episode, the arterial oxygen saturation transiently decreased to $93 \%$, but soon recovered to $98 \%$. Anesthesia was maintained with sevoflurane and 50\% oxygen in air. A nasogastric tube was placed, and nearly $100 \mathrm{ml}$ of bile-stained gastric fluid was drained. A small amount of greenish fluid was aspirated out of the endotracheal tube. Then, the surgery started with the patient in the right lateral decubitus position. After peritoneal insufflation with carbon dioxide $\left(\mathrm{CO}_{2}\right)$, the peak inspiratory pressure increased from 21 to $26 \mathrm{mmHg}$. His arterial oxygen saturation has gradually fallen from 98 to $92 \%$ since the introduction of $\mathrm{CO}_{2}$. Although no more gastric fluids or secretions were suctioned through the endotracheal tube, a coarse crackle was heard throughout the right lung field on auscultation. The patient was placed on $100 \%$ oxygen and positive end-expiratory pressure of $5 \mathrm{mmHg}$ was applied. The arterial oxygen saturation rose to $95 \%$. An arterial blood gas analysis, checked at this time on a $\mathrm{FiO}_{2}$ of 1.0 and an $\mathrm{ETCO}_{2}$ of 37, was as follows: $\mathrm{pH} 7.334$, $\mathrm{PaO}_{2} 82.2 \mathrm{mmHg}, \mathrm{PaCO}_{2} 44.2 \mathrm{mmHg}$, bicarbonate $24.9 \mathrm{mEq} /$ $\mathrm{L}$ and $\mathrm{SaO}_{2}$ 95.4\%. Surgery proceeded uneventfully and vital signs were stable during the operation. The total anesthetic time

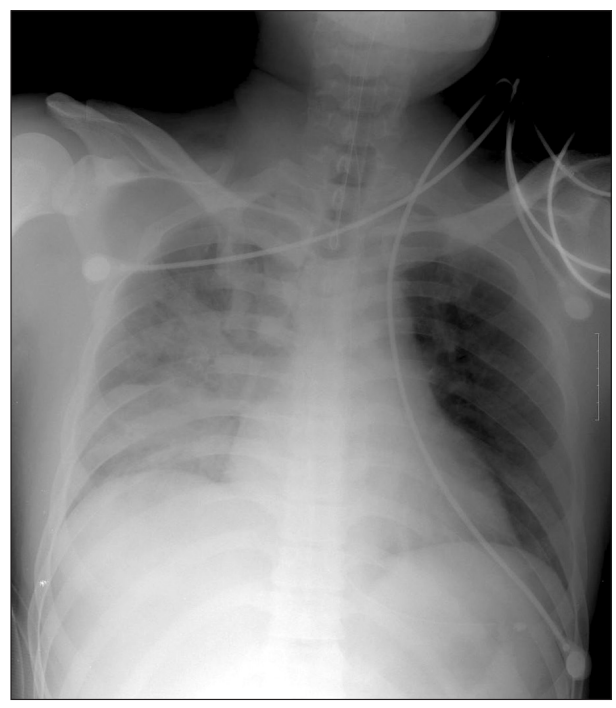

Fig. 1. Postoperative chest radiograph shows consolidation at the right lower lung field and decreased volume of right lung. was 255 minutes and blood loss was estimated at $300 \mathrm{ml}$. The patient was transferred to the intensive care unit and his arterial oxygen saturation which ranged between 93 and 95\% with mechanical ventilation with a $\mathrm{FiO}_{2}$ of 1.0. Chest radiography taken postoperatively has shown patchy consolidation at the right lower lung field and decreased volume of the right lung, suggestive of pulmonary aspiration and atelectasis (Fig. 1). Fiberoptic bronchoscopic examination revealed a large amount of bile-stained fluid and some undigested food particles around the trachea, right main bronchus and lower lobar bronchi, which was aspirated and removed. The arterial oxygen saturation increased to $99-100 \%$ thereafter. His body temperature rose to $38.6^{\circ} \mathrm{C}$ and antimicrobial therapy was initiated. Suction through the endotracheal tube and chest percussions were also frequently applied. On the next day, his temperature dropped to $36.5^{\circ} \mathrm{C}$ and a radiologic improvement on the chest X-ray was observed. The patient was extubated and transferred to a general ward. Supplemental oxygen was delivered via the nasal prong at a rate of $3 \mathrm{~L} / \mathrm{min}$. He did not complain of dyspnea, productive cough or purulent sputum any more. Over the ensuing five days, mild cough and sputum left over were relieved, the arterial hypoxemia resolved and pulmonary infiltration was much improved (Fig. 2). The patient was discharged home seven days after surgery.

\section{Discussion}

Several mechanisms have been suggested to explain FIC. These theories include inhibition of the central sympathetic tone and reflex bronchoconstriction [7], pulmonary chemoreflexes

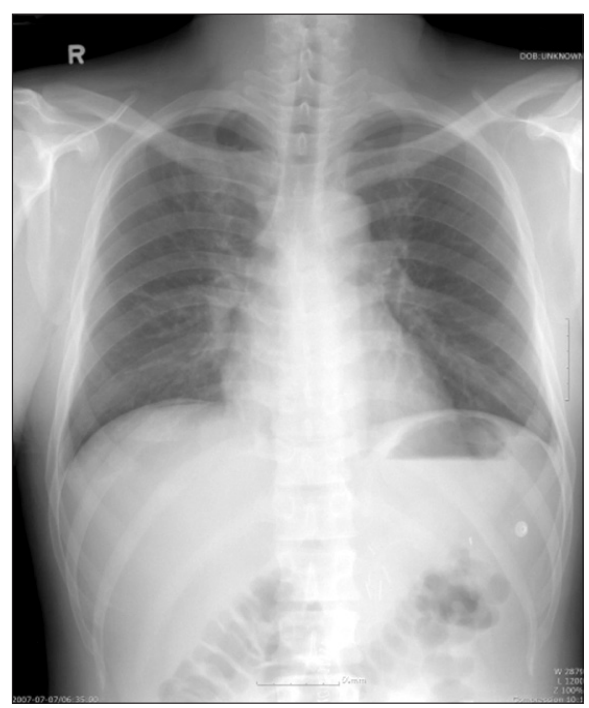

Fig. 2. Chest radiograph taken on the day of discharge shows resolution of the infiltration of right lung. 
mediated by vagal C-fiber receptors near pulmonary vessels or irritant receptors (rapidly adapting receptors) [8,9], stimulation of irritant receptors following the constriction of the tracheal smooth muscles and deformation of the tracheobronchial wall [8], vocal cord spasms [10], and release of histamine or neuropeptides from prejunctional $\mu$-opioid receptors [11]. Although FIC can bring about adverse events associated with increased intracranial, intraocular or intraabdominal pressures, in most cases, it lasts for a moment and scarcely does any harm to patients. Until now, there have been only 2 published reports of FIC with morbidities. Tweed and Dakin [12] described a case of conjunctival and periorbital petechiae produced by explosive coughing after bolus injection of fentanyl. Ambesh et al. [13] made a report on a significant airway obstruction accompanying intravenous fentanyl injection and vigorous cough in a child with arteriovenous malformation of the tongue and hypopharynx.

The present case is a report of serious complication of FIC. In this case, we can speculate that heavy cough, provoked by intravenous administration of fentanyl, has raised patient's intraabdominal pressure and caused vomiting, pulmonary aspiration and pneumonia. The fact that he has coughed soon after the injection of fentanyl and there was no other known causative factor of the cough supports our assumption. Patient's bronchoscopic findings of undigested food particles around the trachea and bronchi, despite more than eight hours of fast suggest that his gastric emptying must have been delayed. His anxiety about the surgery, as well as a history of diabetes mellitus, might contribute to slow gastric emptying [14].

This case suggests that FIC should be avoided in certain groups of patients on whom it may have a detrimental effect. These patients include those with raised intracranial or intraocular pressure, severe airway responsiveness, and increased risk of vomiting or aspiration. Various methods have been recommended to reduce the incidence of FIC. Intravenous administration of dexmedetomidine, lidocaine, ephedrine or priming dose of fentanyl, and aerosol inhalation of salbutamol, beclomethasone or sodium chromoglycate proved to be helpful [1,2,4-6]. Prolonged injection time may also be considered [3]. In addition, the use of a priming dose of vecuronium can be readily applied during induction of anesthesia [15].

Although FIC is mostly temporary and insignificant, it can lead to critical adverse events in patients with risk factors. The current case demonstrates aspiration pneumonia as a complication of severe cough.

\section{References}

1. Gu C, Zhou M, Wu H, Li F, Tang Q. Effects of different priming doses of fentanyl on fentanyl-induced cough: a double-blind, randomized, controlled study. Pharmacol Rep 2012; 64: 321-5.

2. He L, Xu JM, Dai RP. Dexmedetomidine reduces the incidence of fentanyl-induced cough: a double-blind, randomized, and placebocontrolled study. Ups J Med Sci 2012; 117: 18-21.

3. Lin JA, Yeh CC, Lee MS, Wu CT, Lin SL, Wong CS. Prolonged injection time and light smoking decrease the incidence of fentanyl-induced cough. Anesth Analg 2005; 101: 670-4.

4. Pandey CK, Raza M, Ranjan R, Lakra A, Agarwal A, Singh U, et al. Intravenous lidocaine suppresses fentanyl-induced coughing: a doubleblind, prospective, randomized placebo-controlled study. Anesth Analg 2004; 99: 1696-8.

5. Agarwal A, Azim A, Ambesh S, Bose N, Dhiraj S, Sahu D, et al. Salbutamol, beclomethasone or sodium chromoglycate suppress coughing induced by iv fentanyl. Can J Anaesth 2003; 50: 297-300.

6. Uvelin A, Rakic G. Guidelines for prevention of fentanyl-induced cough. Acta Anaesthesiol Scand 2009; 53: 1228-9.

7. Reitan JA, Stengert KB, Wymore ML, Martucci RW. Central vagal control of fentanyl-induced bradycardia during halothane anesthesia. Anesth Analg 1978; 57: 31-6.

8. Yasuda I, Hirano T, Yusa T, Satoh M. Tracheal constriction by morphine and by fentanyl in man. Anesthesiology 1978; 49: 117-9.

9. Paintal AS. Mechanism of stimulation of type J pulmonary receptors. J Physiol 1969; 203: 511-32.

10. Benthuysen JL, Smith NT, Sanford TJ, Head N, Dec-Silver H. Physiology of alfentanil-induced rigidity. Anesthesiology 1986; 64: 440-6.

11. Lou YP. Regulation of neuropeptide release from pulmonary capsaicin-sensitive afferents in relation to bronchoconstriction. Acta Physiol Scand Suppl 1993; 612: 1-88.

12. Tweed WA, Dakin D. Explosive coughing after bolus fentanyl injection. Anesth Analg 2001; 92: 1442-3.

13. Ambesh SP, Singh N, Srivastava K. Fentanyl induced coughing caused life-threatening airway obstruction in a patient with arteriovenous malformation of tongue and hypopharynx. Int J Anesthesiol 2009; 20: 7.

14. Asai T. Editorial II: Who is at increased risk of pulmonary aspiration? Br J Anaesth 2004; 93: 497-500.

15. Oshima T, Kasuya Y, Okumura Y, Murakami T, Dohi S. Identification of independent risk factors for fentanyl-induced cough. Can J Anaesth 2006; 53: 753-8. 